\title{
Assessing Wild Pollinators in Conventional Agriculture: A Case Study From Maine's Blueberry Industry
}

\author{
Samuel Hanes' \\ Department of Anthropology, University of Maine, ME, United States \\ Kourtney Collum \\ College of the Atlantic, Bar Harbor, ME, United States \\ Frank Drummond \\ School of Biology and Ecology, University of Maine, ME, United States \\ Aaron Hoshide \\ School of Economics, University of Maine, ME, United States
}

\section{Abstract}

Increasing use of functional agrobiodiversity, organisms that help farmers, is crucial to improving resilience of conventional agriculture in industrial countries. Literature suggests acquiring local ecological knowledge on these species is a formidable barrier. The present study uses interview data to explore farmers' acquisition of local ecological knowledge concerning wild bees, as well as farmer's use and conservation of wild bees. Wild bees are important crop pollinators and an alternative or supplement to declining commercial honeybees. We found that high uncertainty over wild bees prompts risk aversion, slowing use and conservation. However, to acquire local ecological knowledge, farmers eschew time-consuming assessment and instead develop rules of thumb that mesh with and draw on their use of honeybees. These findings illustrate the complex way in which farmers adapt to the challenge of acquiring local ecological knowledge of functional agrobiodiversity in a conventional agricultural system.

Keywords: ecological knowledge, agriculture, pollination, agrodiversity

1 Corresponding author: samuel.hanes@maine.edu. 


\section{Introduction: The challenge of assessing agrobiodiversity}

Sustainable agriculture requires increasing diversity in farming systems (Kremen et al., 2012). Functional agrobiodiversity, which is critical to diversification, is defined as species diversity that farmers use; this is in contrast to biodiversity, which has no direct value to farmers. Unlike crop genetic diversity, functional agrobiodiversity refers to the wide variety of non-crop species that boost farm production, from beneficial insects to soil microbiota (Bianchi et al., 2013). While greater use of these organisms is critical to alternative food movements, intensifying the use of functional agrobiodiversity is also integral to broader agricultural sustainability efforts in industrial countries (Sutcliffe et al., 2015; Tscharntke et al., 2012). Multifunctional agriculture, which focuses on multiple uses of farmland, emphasizes the importance of ecosystem services, many of which require greater functional agrobiodiversity conservation (Tamásy, 2013; Wilson, 2009). Agroecological intensification programs in Europe (i.e., management areas and systems designed to make conventional farming more sustainable) use more functional agrobiodiversity than conventional agriculture (Swift et al., 2004; Jackson et al., 2007). Both multifunctional agriculture and agroecological intensification are middle ground spaces between conventional and alternative farming (Marja et al., 2014; Perfecto \& Vandermeer, 2010).

Wild bees are a crucial type of functional agrobiodiversity in great need of attention, as global trends in bee decline threaten insect-pollinated crops (Potts et al., 2010). Globally, one-third of all crops depend on insect pollination, including many fruits, vegetables, and nuts (Klein et al., 2007). Typically, pollination has underutilized diversity. A single species, the honeybee (Apis mellifera), is by far the main domesticated crop pollinator in the United States (US) and Europe (van Engelsdorp \& Meixner, 2010), and both US and European honeybees have been in decline for decades (Neumann \& Carreck, 2010). US hive numbers have dropped over $60 \%$ since 1960 and 40\% since 1980 . Winter losses have gone from $10-15 \%$ to 20-30\% after Colony Collapse Disorder (CCD) began in 2007 (Seitz et al., 2015). Honeybees today suffer from increased pesticide exposure, longer transit distances between pollination stopovers, poorer diet (often due to spending more time in large monocultures with lower nutritional value, and due to diverse habitat loss), limited genetic diversity, and more diseases, parasites, and pests (Potts et al., 2010). One way to diversify pollination is through greater reliance on, and conservation of, wild bees (Venturini et al., 2017). There are over 4,000 species of bees in the US alone, many of which are effective crop pollinators (National Resource Council of the National Academies, 2007). Wild bees are already significant pollinators (Winfree et al., 2008) and conservation efforts can increase their numbers (Brosi et al., 2008). Moreover, since wild bees increase and stabilize yields even when farmers use 
honeybees (Brittain et al., 2013), increasing their use is important globally (United Nations Environment Programme [UNEP], 2010). Yet, despite these benefits, conventional farmers rarely invest in wild bees in a systematic way.

Acquiring local ecological knowledge on functional agrobiodiversity is potentially a major barrier to more sustainable agriculture in industrial countries (Hilimire, 2011; Iles \& Marsh, 2012). One of the main advantages of conventional farming inputs is that they replace complex interactions with simpler ones, making it easier to capture feedback on their effectiveness over shorter time spans. With functional agrobiodiversity, greater complexity and associated time costs arise because of the difficulty of observing and assessing these species at multiple spatial and temporal scales. Conserving functional agrobiodiversity requires on-farm, landscape-scale, and regional approaches, due to the mobility of the organisms (Gonthier et al., 2014). Species' populations may fluctuate a great deal annually, further complicating assessment. Despite these challenges, Vermeulen et al. (2013) note that "uncertainty does not preclude robust decisions on adaptation actions" (p. 8361) in agriculture. We need more studies exploring whether local ecological knowledge acquisition is impeding the conservation and use of functional agrobiodiversity.

This paper asks whether difficulty acquiring local knowledge is a barrier to farmers' intensification of wild bee conservation and use in the blueberry industry in Maine, US. To answer this question, we explore how farmers acquire knowledge on their local wild bee populations, especially their number and effectiveness. We also examine how they are presently conserving and using wild bees. The related question of why farmers choose to conserve wild bees is outside the scope of this paper; we are not examining farmer motivation. All of the farmers interviewed for this project are conserving and using wild bees to some extent. Our aim is to assess the extent to which local knowledge acquisition is a barrier to conserving and using wild bees.

The answer to this question depends in part on whether farmers practice maximizing or "satisficing" knowledge acquisition. Rational actor theory predicts that people will strive to maximize benefits by trying to acquire perfect knowledge of costs and benefits (Elster, 1986). Further, it suggests that farmers will find maximizing agrobiodiversity knowledge too time consuming, inhibiting conservation. In contrast, bounded rationality theory predicts that when people are faced with complex decisions and incomplete knowledge, they will "satisfice," or gather just enough information to make "good enough" decisions (Simon, 1997). Bounded rationality suggests that people generally avoid risk in uncertain situations by taking incremental action when they can. The literature on farmer behavior echoes these two observations from bounded rationality. Prospect theory, which scholars developed to explain responses to risk and uncertainty, and which is widely used in quantitative approaches to farmer behavior, also predicts risk-avoiding incrementalism (Moss, 2010). Many studies show that farmers prefer fast, simple 
environmental assessment that leads to rule of thumb, or "good enough" decisionmaking guides (Franz et al., 2010; Öhlmér et al., 1998). If farmers can successfully satisfice with wild bees, then knowledge acquisition may not be a significant barrier to intensifying use and conservation.

\section{Field site}

To better understand farmers' acquisition of local ecological knowledge concerning wild bees, we studied Maine's lowbush blueberry industry. Lowbush blueberry is grown only in Maine and adjacent Canada and has a different production system from the more widespread highbush blueberry. Pollination diversification is critical since the industry is highly honeybee dependent. Only 500 honeybee hives entered Maine in 1960, but honeybee imports rose steadily after this; there are now more than 77,000 hives in Maine, which has been a major driver of higher yields. Other increasing inputs (e.g., herbicides, insecticides, fungicides, fertilizer, and irrigation) have also helped to raise Maine's production from 6.8 million $\mathrm{kg}$ in 1950 to over 36.3 million kg today, with little spatial expansion (Yarborough, 2015). Almost all of Maine's honeybees come from beekeepers overwintering their bees in Southern states. One reason for high hive rentals is that blueberries have an enormous number of bell-shaped flowers with poricidal anthers that are difficult for honeybees to pollinate (Bell et al., 2009). Honeybees are only able to transfer a few pollen grains per flower visit (Drummond, 2016), and blueberry pollination requires multiple pollen grains to produce full-sized fruit (Bell et al., 2009). Lowbush blueberry is also a native plant with coevolved native pollinators (Jones et al., 2014). This species is not cultivated; forest or old farmland is cleared and managed to increase blueberries naturally growing in these areas (Drummond et al., 2009). Blueberries are $100 \%$ pollinator dependent; without insect pollination they will not produce fruit (Bell et al., 2009). Farmers' standard practice is to monitor bloom and place honeybees in fields when around 10\% of flowers have begun blooming (Drummond, 2002). However, different plants in the same field bloom at different times (White et al., 2012). If honeybees are placed in a field too early, they will find other places to forage, leading farmers to observe too few honeybees in their fields (Drummond, 2002). Wild bee habitat can be quite good around some fields; however, the largest fields in eastern Maine are typically surrounded by coniferous forest with few bees and lower field-to-edge ratios (Bushmann \& Drummond, 2015). Maine Cooperative Extension ${ }^{2}$ advises farmers to rent seven to 10 honeybee hives per hectare of blueberries, depending on the surrounding habitat (Drummond, 2002); they have promoted wild bee use and conservation for the past 20 years, making this an ideal study site.

2 Cooperative Extension is the organization at US Land Grant Universities dedicated to providing information and outreach to the agricultural community; it was initiated by the Smith-Lever Act in 1914 . 


\section{Methods}

To better understand famers' knowledge acquisition and conservation of wild bees, we conducted 26 in-depth, in-person, semi-structured interviews with Maine blueberry farmers. Initial interviewees were chosen because of their current involvement with scientific projects on wild bees; others were recruited via snowball sampling. The rationale for choosing these farmers was to target early adopters of innovation in using wild bees (Rogers, 2003). Sampled interviewees were selected as representative of the industry and farm size. Interview questions focused on pollination practices, including wild bee use and knowledge acquisition. We conducted interviews between October 2012 and April 2015. Only one person declined an interview request. All interviews took place at farmers' farms and lasted approximately one to three hours. Interviews were digitally recorded when possible, with permission, and transcribed, as were field notes when recording was impossible. We used attribute and pattern coding to inductively code interviews in MAXQDA. Table 1 contains the interview prompts. All results derive from qualitative analysis of the interviews, with one exception; we conducted a survey on pollination practices at grower meetings and on-farm interviews from 2012 to 2013. We used this data source to assess wild bee conservation and monitoring practices in the industry. The 80 survey responses represented no less than $15 \%$ of the industry managing over $90 \%$ of the crop area. We conducted statistical analyses (ordinary least squares and probit regressions) in SPSS to determine how crop management practices and farmer sociodemographic characteristics influence wild bee conservation and monitoring (Table 2). ${ }^{3}$

\section{Table 1. Interview protocol and selected survey questions}

\begin{tabular}{|l|}
\hline Interview protocol \\
\hline 1. How did you pollinate your fields when you started growing blueberries? \\
\hline 2a. How many honeybee hives do you rent per acre today? \\
\hline 2b. Where do you get them? \\
\hline 2c. Where do you put them? \\
\hline 2d. How would you assess their quality? \\
\hline 2e. What problems have you encountered? \\
\hline 3a. Do you do anything to attract wild bees to your fields, and if so, what? \\
\hline 3b. Do you do anything to enhance wild bee habitat, and if so, what? \\
\hline 3c. Do you use nest boxes? \\
\hline $\begin{array}{l}\text { 3d. Do you watch wild bees in and around your fields to assess their effectiveness? } \\
\text { How do you do this? }\end{array}$ \\
\hline 4. What else have you done that you think affected wild bees, positively or negatively? \\
\hline
\end{tabular}

3 For full results from this survey, see Hanes et al. (2015). 
5a. What percentage of your fruit set do you think comes from wild bees?

$5 b$. Do you think this has changed, and if so, why?

5c. How do you estimate wild bees' contribution to fruit set?

$5 d$. How does wild bees' contribution affect your honeybee rentals?

5e. Could wild bees contribute more if you had no rentals?

5f. If you don't rent honeybees, how much do you think you could increase your fruit set with rented bees?

6. What are your main concerns about pollination?

7. Do you think the industry will pollinate differently in 10 or 20 years?

\section{Selected survey questions}

1. Total (both fruit and prune) acres of blueberries you manage?

2. Acres you rely exclusively on native bees?

3. Percent of your fruit set you feel comes from native bees?

4. Honeybee hives rented per year?

5. Bumble bee quads rented per year?

6. How important do you think native bees are for pollinating blueberries in Maine? (Likert scale: very important to very unimportant)

7. Did you do any of the following native bee enhancements this year? Yes or No.

7a. Own honeybees

7b. Use leaf cutting bee nest boxes or bumble bee nesting items

7c. Plant wildflowers or bee meadows specifically for pollinators

7d. Alter pesticides to help pollinators

7e. Leave deadwood standing for pollinators

8. Monitor native bees in any way?

9. Rent fewer bees due to neighbors' spillover

10. Ease of monitoring native bees (Likert scale: strongly agree to strongly disagree)

11. Surrounding landscape is farmland? Yes or No.

12. Years grown blueberries?

13. Pest management style? (IPM, organic, no spray, traditional)

14. Education level?

Table 2. Probit and linear regression parameter estimates (and p-values) for native bee monitoring and total number of native bee habitat enhancements in Maine wild blueberry from 2012-2013 survey

\begin{tabular}{|l|l|l|}
\hline $\begin{array}{l}\text { Wild Blueberry Farm/Producer } \\
\text { Characteristic }\end{array}$ & $\begin{array}{l}\text { Monitor Native Bees } \\
\text { (Probit: 1 = Yes; 0 = No) }\end{array}$ & $\begin{array}{l}\text { Number of Enhancements } \\
(\mathbf{0} \rightarrow 5)\end{array}$ \\
\hline Respondents (\% of total) & $29(36 \%)$ & $68 \geq 1(85 \%)$ \\
\hline Years grown & \multicolumn{1}{|c|}{$+(0.052)^{\star}$} & $\mathrm{ns}$ \\
\hline Increasing education & $\mathrm{ns}$ & $0.110(0.046)^{\star *}$ \\
\hline Pollinate w/commercial bees & $\mathrm{ns}$ & $\mathrm{ns}$ \\
\hline
\end{tabular}




\begin{tabular}{|l|l|l|}
\hline $\begin{array}{l}\text { Wild Blueberry Farm/Producer } \\
\text { Characteristic }\end{array}$ & $\begin{array}{l}\text { Monitor Native Bees } \\
\text { (Probit: 1 = Yes; } 0=\mathbf{N o})\end{array}$ & $\begin{array}{l}\text { Number of Enhancements } \\
(\mathbf{0} \rightarrow \mathbf{5})\end{array}$ \\
\hline Own honeybees & $\mathrm{ns}$ & $\mathrm{ns}$ \\
\hline Quads/acre & $\mathrm{ns}$ & $1.940(0.022)^{\star \star}$ \\
\hline Pollinator practices (5) & $\mathrm{ns}$ & $\mathrm{n} / \mathrm{a}$ \\
\hline Monitor bees & $\mathrm{n} / \mathrm{a}$ & $0.547(0.057)^{\star}$ \\
\hline Monitoring wild bees less easy & & $\mathrm{ns}$ \\
\hline Native bees less important & $\mathrm{ns}$ & $-0.306(0.049)^{\star \star}$ \\
\hline Total crop area & $\mathrm{ns}$ & $\mathrm{ns}$ \\
\hline Rent fewer bees - spillover & $\mathrm{ns}$ & $0.765(0.032)^{\star \star}$ \\
\hline Organic & $\mathrm{ns}$ & $\mathrm{ns}$ \\
\hline Farmland landscape & $\mathrm{ns}$ & $0.505(0.072)^{\star}$ \\
\hline
\end{tabular}

Note. $n=80 ; \mathrm{ns}=$ not significant. For probit note sign (+ or - ) and not parameter estimate. Significance at $0.10^{\star}$ and $0.05^{\star \star}$ level. Number of enhancements $\left(r^{2}=0.342\right)$.

\section{Results}

\section{Uncertainty regarding honeybees}

To understand the conservation and use of wild bees, it is necessary to understand how farmers perceive honeybees. A theme of pervasive uncertainty regarding the exact contribution of honeybees to yield was observed throughout the interviews. Some farmers stated that it was difficult to know how many hives to rent because it was difficult to calculate precisely the influence of honeybees on yield. Even the farmer with the most precise method for determining hive rental numbers was equivocal; he ${ }^{4}$ stated that he "micro-managed" each field depending on the amount of wild pollinators present, and that he estimated good weather for half of the bloom period and calculated how many hives he would need based on this approximation. However, this farmer also stated that he did not know the maximum hive density he should be using, although he hoped to determine this.

The reasons for uncertainty fell into several main categories. One was weather. Farmers could not predict the exact size of their "pollination window." Cold, rainy days prohibit pollination because honeybees will not fly. Cold, wet springs are common in Maine, so farmers often want more honeybees to pollinate shorter windows. The effect of wild bees was also difficult to judge and this made it challenging for farmers to calculate their pollination needs. In addition, many farmers did not know the cutoff point at which an extra hive was redundant. However, most farmers were certain about the basic relationship: honeybees raise yields. Only one farmer

4 Due to the small number of women who are primary managers in this industry, we refer to all interviewees as "he" to preserve confidentiality. 
expressed any doubt about this: "I'm assuming that the $\$ 200$ plus per acre that I spend for pollination is generating increased production. I don't know that for a fact." While most farmers felt confident about the general relationship between honeybees and increased yields, they were less certain about exact numbers.

Farmers responded to uncertainty about honeybees in four main ways. First, they assessed honeybee "hive strength," or a hive's number of active workers. Farmers expressed certainty regarding their ability to at least qualitatively assess hive strength. They were able to determine whether a hive was "weak" by the number of bees leaving it in good weather and by walking their fields to observe bee activity. No one reported any systematic attempts to measure honeybee strength by counting bees in the field, despite Cooperative Extension publishing information on how to do this. Weak hives are rare. Farmers reported changing beekeepers if this happened and they were all pleased with the present quality of their hives. Several mentioned that hives had been stronger in recent years due to better bee husbandry practices post-CCD. Farmers frequently expressed admiration for honeybee numbers and productivity, using phrases such as "really hot" or "ready to work" to describe hives. Although farmers' observations of hive strength were not systematic, most felt they were able to determine whether a beekeeper was supplying decent hives. A second strategy was small-scale experimentation leading to gradual change. Most farmers reported gradually changing hive rental numbers. Usually these were small, incremental changes, except when a major event took place, such as switching to organic certification. Hive rental numbers also coincided with overall management strategies; farmers with high inputs and high yields rented more hives per hectare.

A third strategy was to rely on rules of thumb. Several farmers felt that their wild bees gave them 2.47 honeybee hives equivalent of pollination per hectare and so would lower rentals by this amount per hectare. Some farmers reported using fewer hives than Cooperative Extension recommended because they thought their hives were stronger or because they did not want to spend that much money. Other farmers mentioned "going by the book" - that is, following Cooperative Extension's factsheets closely. Rules of thumb were modified by observations regarding effectiveness that were built up over time.

A fourth strategy was to rely on information from processors. There are three large processors in Maine, each of which also manages large areas of blueberry farms. Farmers frequently utilize information from such sources, partly because large companies have more capital to spend on innovation. Moreover, farmers often rent bees through their processor and follow their recommendations on rental numbers. Farmers also share information with one another. Processors give them a set price for blueberries, which means that farmers do not see themselves as competitors. Processors do compete, but they have to unite to compete as an industry with other frozen fruits. Given this foreknowledge regarding price, farmers often come early and stay late at Cooperative Extension meetings to informally share information 
and compare strategies. Such meetings do not typically have time set aside for this, with the exception of the largest summer meeting that has scheduled lunch and social time. These meetings are important as farmers are geographically dispersed over a wide area and have few opportunities to meet face-to-face.

All four strategies show farmers satisficing with honeybee knowledge acquisition and rarely using systematic methods to assess hive strength, despite having ready access to these. Instead, they use rules of thumb and change gradually. Relying on trusted knowledge sources is another way to avoid costly knowledge acquisition. All interviewees' practices were more consistent with bounded rationality theory than rational actor theory, which would predict farmers using Cooperative Extension's hive strength assessment tools much more frequently.

\section{Uncertainty regarding wild bees}

Farmers expressed even more uncertainty regarding the contribution of wild bees to blueberry yields. Wild bee populations are difficult to assess. Bees are small, diverse, fast moving, and their populations vary annually. Species are hard to tell apart, even for experts, although some groups, such as bumble bees, are larger and more identifiable in the field. A few farmers mentioned specific families of bees, such as mason bees and leafcutters, and most mentioned identifying bumble bees. A few small farmers who did not rent honeybees maintained that they achieved close to $100 \%$ of their pollination from wild bees; however, these were all low yielding farms. Data from the 2012-2013 survey showed that conventional farmers felt that $40 \%$ of their pollination or "fruit set" came from wild bees; likewise, the farmers we interviewed generally felt that wild bees were significant contributors. Our field data shows that this estimate is probably accurate (Asare et al., 2017), even though interviewees and survey respondents consistently expressed high uncertainty regarding their own estimates.

Further complicating any assessment of the contribution of wild bees, spillover pollination from surrounding farmers' rented hives is common. Only one of the conventional farmers we interviewed used no honeybees in a field that was isolated enough for spillover pollination from rented honeybees to be unlikely. Even though this field had a surrounding wild bee habitat equal to seven times the area of the field and the farmer had observed high numbers of bumble bees, it took deer-damage during the prune year to lead the farmer to decide to experiment with using no hives, as yields were depressed anyway. For the past two crop cycles, the farmer has obtained yields that are close to Maine averages (United States Department of Agriculture, 2012). This situation was the only one described by an interviewee that provided any indication of the extent of wild bee habitat required to completely substitute for rented honeybees. The absence of similar cases exacerbates farmer uncertainty over wild bees' contribution to yield. Spillover may also make farmers 
hesitant to experiment with reducing honeybee rentals; most do not want to appear to be free riding on neighboring farmers' hives. Farmers described such practices as "cheap," saying everyone needed to "pay their fair share" by renting enough hives.

Cooperative Extension has developed assessment tools to enable farmers to acquire local ecological knowledge of wild bees. These involve setting up a meter square outline and counting bees within it for a set time. Survey data showed only 36\% of farmers monitored wild bees in any way. Monitoring correlated positively with how long farmers had been growing blueberries, but not with any other farm or demographic variables (Table 2). Only one interviewee claimed to monitor wild bees in a fashion similar to the way recommended by Cooperative Extension:

We do what they [Cooperative Extension] suggest with this kind of square meter box. Put that over the plant and then just look, pretty casually and not scientifically. Sometimes you get nervous as we don't have bees and putting out a crop so that's one way to kind of go and just see and you see, okay, weve had two visits in a minute alright so it doesn't feel like there's a lot of bees but according to the university that's adequate you know.

Other interviewees reported monitoring wild bees more informally.

This raises the question of how these farmers are able to accurately estimate wild bees' contribution to their yield. In part, they do this by thinking about what they get from honeybees. By adjusting their hive rentals and seeing the results, they can guess what wild bees are contributing. Some growers manage multiple fields, likely making this strategy more effective. The longstanding relationship between farmers and Cooperative Extension and Univeristy of Maine entomologists is another factor that may explain farmers' ability to assess wild bees' contribution to their yield. The industry has a long history of generally positive interaction with entomologists dating back to a University of Maine entomologist's 1922 study of the blueberry maggot fly's life history (Drummond \& Collins, 1999). Trusting entomologists' presentations and publications on wild bees probably helps farmers to develop accurate assessments.

As with honeybees, when farmers assess the role of wild bees, they are faced with high uncertainty for a key input. They respond by developing rules of thumb. One widely mentioned rule of thumb was that wild bees contribute a honeybee hive worth of pollination per acre ( 2.47 hives/hectare) where habitat is good. The following statement exemplifies this view:

With 4 hives to the acre you could get up to like $80 \%$ of pollination rate. But to get that last $20 \%$ of pollination rate, you had to get like another 6 hives. So really, at the 4 hives and about $80 \%$ you're really starting to get diminishing returns. I figure because my fields are not like down on the barrens, I figure I get about a hive's worth of wild pollination and then I put on another 3 hives per acre of honeybees to equal about 4 hives to the acre and get my $80 \%$. 
This rule of thumb is particularly important because it integrates wild bees and honeybees.

The 2012-2013 survey revealed that $85 \%$ of farmers were conserving wild bees in at least one of several ways. Easy, low-cost actions were the most common: leaving deadwood standing for nest sites (65\%), altering pesticide use to aid wild bees (59\%), avoiding mowing wildflowers (53\%), setting up nest boxes (20\%), and planting wildflowers (14\%). However, most farmers interpreted the planting question to mean anything in their home garden and not large-scale pollinator pastures (Cooperative Extension has a guide to designing these). The pattern is one of widespread, but small-scale, conservation.

Statistical analysis showed that farmers who reported doing more of the five conservation actions listed above shared several characteristics (Table 2). They tended to have more formal education and to be more likely to use bumble bees. Farmers who reported taking more conservation actions were more likely to respond that wild bees were "important" or "very important" to Maine's blueberry industry and they were also more likely to monitor their wild bees.

Farmers have tried to diversify pollination in other ways. A few reported experimenting with commercial bumble bees (Bombus impatiens Cresson); however, most experimented in a limited fashion and then quickly stopped. Some observed few bees in their fields, others saw few leaving the hives, and some commented that bumble bees were less robust and weather tolerant than they had hoped. Although some farmers mentioned yields, their main complaint was a lack of visible bees. Bumble bees are far less numerous per hive than honeybees, but they are much more efficient than honeybees, and so farmers may have underestimated the effectiveness of bumble bees. Bumble bees actually increase the effectiveness of honeybees by releasing more pollen (Drummond, 2016). Rather than rely on their own limited observations, this suggests that farmers should monitor the effect of using bumble bees over several years, drawing on information obtained from Cooperative Extension's website (Greenleaf \& Kremen, 2006).

In the late 1990s and early 2000s, Maine farmers experimented with two other approaches to diversifying pollination resources. The first was owning and managing their own honeybee colonies; however, it was found that these hives performed poorly compared to rented hives. Only a few farmers tried this approach, and all stopped after they lost hives and realized that managing honeybees was a yearround endeavor. In our 2012-2013 survey, only 18\% of blueberry producers owned honeybees. The second strategy was using alfalfa leafcutting bees (Megachile rotundata), a solitary bee that takes readily to human-made nesting structures and can be managed in large numbers. Two large companies and a few other small farmers tried them, but they required too much management at a time when farmers 
were conducting intensive blueberry management. As with wild bee conservation and bumble bee use, it seems that farmers are reluctant to invest substantial time in intensive forms of diversification.

Farmers find wild bees hard to assess and they appear to respond by satisficing. Cooperative Extension provides detailed methods for assessing wild bee populations but, as with hive strength measurement tools, farmers rarely use them. Instead, they develop rules of thumb. They adopt and intensify conservation gradually. They rely on trusted information sources, mainly Cooperative Extension, but only in a general sense. These actions are all consistent with bounded rationality.

\section{Uncertainty regarding national-scale honeybee trends}

A critical knowledge requirement for wild bee investment and conservation is the ability to accurately assess national honeybee health trends. Farmers' concerns about pollination were mostly related to CCD, honeybee health in general, and wild pollinator decline. Many farmers stated that they had no concerns about pollination; however, of these, some revealed that weather and price were concerns. Most of the farmers who stated they had no concerns about national honeybee trends explained that beekeepers had improved their bee husbandry as a response to CCD. These farmers sometimes linked better honeybee husbandry and hive strength to higher prices. Another theme was that CCD was exaggerated or unreal. According to some farmers, the number of hives in the US in the 1950s was unusually high; when viewed alongside the fact that the number of honeybee hives managed worldwide has risen slightly, or stayed stable, due to increases in Asia (UNEP, 2010), this made current US declines look less severe. As CCD is not entirely understood by scientists, this also opened room for debate. The absence of consensus among blueberry farmers demonstrates the difficulty of gathering feedback on national honeybee health trends and CCD. This is significant, as farmers' lack of concern may inhibit the conservation of wild bees.

To understand farmers' perceptions of national-scale honeybee health, it is important to understand how they assess honeybee health. Price proved to be an important signal for interviewees. Few farmers expressed concern about current hive rental prices, which may be due to the nature of the crop. The cost of honeybee rentals has risen in Maine from $\$ 30$ per hive in 1990 to $\$ 100$ per hive in 2016 (Drummond, unpublished data). This rise in price is partly due to increased demand, but it also reflects the need to replenish higher winter losses. Higher costs are not spread uniformly; early blooming and non-honey producing crops appear to bear more of the costs (Rucker et al., 2012). Maine blueberries bloom early (but much later than almonds) and they produce good honey, which may help to keep hive rental prices low. Seventy percent of all US honeybees go to California for the almond bloom in February, just as beekeepers are splitting hives to increase their numbers. Hive rental prices in the California almond industry increased by as much as $300 \%$ between 2001 and 2009 (Rucker et al., 2012). 
The bulk of the cost increase experienced by blueberry farmers may be due to higher transportation fees from beekeepers traveling further, rather than the increased cost of treating bees for pests and pathogens (Rucker et al., 2012). Although economists debate this, almonds and other early blooming crops may also be absorbing much of the price rise from higher winter losses, hive regeneration costs, and transport, thus subsidizing later blooming crops. This suggests that blueberry farmers may be overly optimistic about national honeybee health trends if they rely solely (or even heavily) on price as a signal for understanding the issue.

From the perspective of some farmers, an ample honeybee supply is another sign that there is no national-scale problem. Thus far, Maine farmers have been able to obtain all the honeybees they need; however, this could change quickly. Californian almond farmers have begun buying up beekeeping businesses. In 2015, Paramount Farming Company purchased approximately 50,000 hives to manage themselves from one of the US's largest beekeepers. The new owners chose to bring many of these to Maine in 2015 and 2016, but it is unknown whether they will continue to do so. If they do not, Maine could face a serious shortage of honeybees for the first time.

\section{Discussion}

We find that bounded rationality theory explains how Maine farmers respond to the uncertainty generated by their pollination system's complex-they acquire and use local ecological knowledge on wild bees. Further, we find that the time required to acquire local environmental knowledge is not always a major barrier to intensifying the use of wild bees. Instead, farmers satisfice by limiting time spent monitoring wild bee populations and use simple observations to develop rules of thumb. They combine these with observations of honeybees' effectiveness to create a fair estimate of wild bees' influence on yield. This knowledge acquisition system enables farmers to make decisions that they feel are adequate. Our findings likely apply to other functional agrobiodiversity conservation practices because, in general, they require acquiring knowledge on more complex systems. We would expect farmers in other crops to also limit time spent acquiring local environmental knowledge and to develop rules of thumb. Increasing functional agrobiodiversity usually lowers reliance on a conventional input, and so the pattern of assessing the two in tandem to augment limited direct population monitoring should be present for other inputs as well. However, in this case, farmers also satisfice with honeybees. This may make it easier to use wild bees, as farmers can develop rules of thumb that mesh the two inputs. For conventional inputs, in which farmers practice maximizing knowledge acquisition, it may be harder to develop combined rules of thumb. Local knowledge acquisition on agrobiodiversity may be more of a barrier in these cases. 
We also found that farmers expressed uncertainty over honeybees. Farmers practice satisficing in regards to hive strength estimates and express uncertainty over the maximum rental rates they need. They develop rules of thumb in both cases, and pursue at least some degree of information sharing to increase their knowledge. Our most unexpected finding was the level of disagreement, and hence collective uncertainty, over long-term national honeybee health trends. The complexity of the subject forces farmers to use satisficing processes here as well. Long-term, nationalscale knowledge acquisition may be as much of a barrier to adopting conservation as acquiring local ecological knowledge.

\section{References}

Asare, E., Hoshide, A. K., Drummond, F. A., Criner, G. K., \& Chen, X. (2017). Economic risks of bee pollination in Maine wild blueberry, Vaccinium angustifolium. Journal of Economic Entomology, 110(5), 1980-92. doi.org/10.1093/jee/tox191

Bell, D. J., Rowland, L. J., Smagula, J., \& Drummond, F. A. (2009). Recent advances in the biology and genetics of lowbush blueberry (Technical Bulletin). Orono, ME: Maine Agricultural Forest Experiment Station, University of Maine.

Bianchi, F. J. J. A., Mikos, V., Brussard, L., Delbaere, B., \& Pulleman, M. M. (2013). Opportunities and limitations for functional agrobiodiversity in the European context. Environmental Science and Policy, 27, 223-231. doi.org/10.1016/j.envsci.2012.12.014

Brittain, C., Kremen, C., \& Klein, A.-M. (2013). Biodiversity buffers pollination from changes in environmental conditions. Global Change Biology, 19(2), 540-547. doi.org/ $10.1111 /$ gcb. 12043

Brosi, B. J., Armsworth, P. A., \& Daily, G. C. (2008). Optimal design of agricultural landscapes for pollination services. Conservation Letters, 1(1), 27-36. doi.org/10.1111/ j.1755-263X.2008.00004.x

Bushmann, S. L., \& Drummond, F. A. (2015). Abundance and diversity of wild bees (hymenoptera: apoidea) found in lowbush blueberry growing regions of Downeast Maine. Environmental Entomology, 44(9), 975-989. doi.org/10.1093/ee/nvv082

Drummond, F. A. (2002). Honeybees and lowbush blueberry pollination (Cooperative Extension Fact Sheet No. 629). Orono, ME: University of Maine.

Drummond, F. A. (2016). Behavior of bees associated with the wild blueberry agroecosystem in the USA. International Journal of Entomology \& Nematology, 2(1), 21-26.

Drummond, F. A., \& Collins, J. (1999). History of insect pest management for lowbush blueberries in Maine. Trends in Entomology, 3, 23-32. 
Drummond, F. A., Smagula, J., Annis, S., \& Yarborough, D. E. (2009). Organic wild blueberry production. University of Maine Agricultural and Forestry Experiment Station Technical Bulletin, 852, 43.

Elster, J. (1986). Rational choice. New York, NY: New York University Press.

Franz, N., Piercy, F., Donaldson, J., Richard, R., \& Westbrook, J. (2010). How farmers learn: Implications for agricultural educators. Journal of Rural Studies, 25(1), 37-59.

Gonthier, D. J., Ennis, K. K., Farinas, S., Hsieh, H.-Y., Iverson, A. L., Batáry, P., Rudolphi, J., Tscharntke, T., Cardinale, B. J., \& Perfecto, I. (2014). Biodiversity conservation in agriculture requires a multi-scale approach. Proceedings of the Royal Society B: Biological Sciences, 281(1791), 1-27. doi.org/10.1098/rspb.2014.1358

Greenleaf, S. S., \& Kremen, C. (2006). Wild bees enhance honey bees' pollination of hybrid sunflower. Proceedings of the National Academy of Sciences, 103(37). 13890-13895. doi.org/10.1073/pnas.0600929103

Hanes, S. P., Collum, K. K., Hoshide, A., \& Asare, E. (2015). Grower perceptions of native pollinators and pollination strategies in Maine's lowbush blueberry industry. Renewable Agriculture and Food Systems, 30(2), 124-131.

Hilimire, K. (2011). Integrated crop/livestock agriculture in the United States: A review. Journal of Sustainable Agriculture, 35(4), 376-393. doi.org/10.1080/10440046.2011.5 62042

Iles, A., \& Marsh, R. (2012). Nurturing diversified farming systems in industrialized countries: How public policy can contribute. Ecology \& Society, 17(4), 178-196. doi.org/10.5751/ES-05041-170442

Jackson, L. E., Pascual, U., \& Hodgkin, T. (2007). Utilizing and conserving agrobiodiversity in agricultural landscapes. Agriculture, Ecosystems \& Environment, 121(3), 196-210. doi.org/10.1016/j.agee.2006.12.017

Jones, M. S., Vanhanen, H., Peltola, R., \& Drummond, F. A. (2014). A global review of arthropod-mediated ecosystem-services in vaccinium berry agroecosystems. Terrestrial Arthropod Reviews, 7, 41-78. doi.org/10.1163/18749836-06041074

Klein, A.-M., Vaissiere, B. E., Cane, J. H., Steffan-Dewenter, I., Cunningham, S. A., Kremen, C., \& Tscharntke, T. (2007). Importance of pollinators in changing landscapes for world crops. Proceedings of the Royal Society B-Biological Sciences, 274(1608), 303-313. doi.org/10.1098/rspb.2006.3721

Kremen, C., Iles, A., \& Bacon, C. (2012). Diversified farming systems: An agroecological, systems-based alternative to modern industrial agriculture. Ecology \& Society, 17(4), 288-306. doi.org/10.5751/ES-05103-170444 
Marja, R., Herzon, I., Viik, E., Elts, J., Mänd, M., Tscharntke, T., \& Batáry, P. (2014). Environmentally friendly management as an intermediate strategy between organic and conventional agriculture to support biodiversity. Biological Conservation, 178(10), 146-154. doi.org/10.1016/j.biocon.2014.08.005

Moss, C. B. (2010). Risk, uncertainty and the agricultural firm. Singapore: World Scientific Publishing Company. doi.org/10.1142/7469

National Resource Council of the National Academies. (2007). Status of pollinators in North America. Washington, DC: National Academies Press.

Neumann, P., \& Carreck, N. L. (2010). Honey bee colony losses. Journal of Apiculture Research, 49(1), 1-6. doi.org/10.3896/IBRA.1.49.1.01

Öhlmér, B., Olson, K., \& Brehmer, B. (1998). Understanding farmers' decision making process and improving managerial assistance. Agricultural Economics, 18(3), 273-290. doi.org/10.1016/S0169-5150(97)00052-2

Perfecto, I., \& Vandermeer, J. (2010). The agroecological matrix as alternative to the landsparing/agriculture intensification model. Proceedings of the National Academy of Sciences of the United States of America, 107(13), 5786-5791. doi.org/10.1073/pnas.0905455107

Potts, S. G., Biesmeijer, J. C., Kremen, C., Neumann, P., Schweiger, O., \& Kunin, W. E. (2010). Global pollinator declines: Trends, impacts and drivers. Trends in Ecology \& Evolution, 25(6), 345-353. doi.org/10.1016/j.tree.2010.01.007

Rogers, E. (2003). Diffusion of innovations (5th ed.). New York, NY: Free Press.

Rucker, R. R., Thurman, W. N., \& Burgett, M. (2012). Honeybee pollination markets and the internalization of reciprocal benefits. American Journal of Agricultural Economics, 94(4), 956-977. doi.org/10.1093/ajae/aas031

Seitz, N., Traynor, K. S., Steinhauer, N. A., Rennich, K., Wilson, M. E., Ellis, J. D., ... van Engelsdorp, D. (2015). A national survey of managed honey bee 2014-2015 annual colony losses in the USA. Journal of Apiculture Research, 54(4), 292-304. doi.org/ $10.1080 / 00218839.2016 .1153294$

Simon, H. A. (1997). Administrative behavior: A study of decision-making processes in administrative organizations (4th ed.). New York, NY: Free Press.

Sutcliffe, L. M. E., Batáry, P., Kormann, U., Báldi, A., Dicks, L. V., Herzon, I., \& Kleijn, D. (2015). Harnessing the biodiversity value of Central and Eastern European farmland. Diversity \& Distributions, 21(6), 722-730. doi.org/10.1111/ddi.12288

Swift, M. J., Izac, A.-M. N., \& van Noordwijk, M. (2004). Biodiversity and ecosystem services in agricultural landscapes-are we asking the right questions? Agriculture, Ecosystems \& Environment, 104(1), 113-134. doi.org/10.1016/j.agee.2004.01.013

Tamásy, C. (2013). Areas of intensive livestock agriculture as emerging alternative economic spaces? Applied Geography, 45(12), 385-391. doi.org/10.1016/j.apgeog.2013.02.012 
Tscharntke, T., Clough, Y., Wanger, T. C., Jackson, L., Motzke, I., Perfecto, I., ... Whitbread, A. (2012). Global food security, biodiversity conservation and the future of agricultural intensification. Biological Conservation, 15 (1), 53-59. doi.org/10.1016/j. biocon.2012.01.068

UNEP (United Nations Environment Programme). (2010). Global honeybee collapse disorder and other threats to insect pollination. Nairobi, Kenya: UNON/Publishing Services Section.

United States Department of Agriculture, National Agricultural Statistics Service. (2012). Statistics by State. Retrieved from: www.nass.usda.gov/Statistics_by_State/

van Engelsdorp, D., \& Meixner, M. D. (2010). A historical review of managed honeybee populations in Europe and the United States and the factors that may affect them. Journal of Invertebrate Pathology, 103(S1), S80-S95. doi.org/10.1016/j.jip.2009.06.011

Venturini, E. M., Drummond, F. A., Hoshide, A. K., Dibble, A. C., \& Stack, L. B. (2017). Pollination reservoirs for wild bee habitat enhancement: A review. Journal of Agroecology and Sustainable Food Systems, 41(2), 101-142. doi.org/10.1080/21683565.2016.1258377

Vermeulen, S. J., Challinor, A. J., Thornton, P. K., Campbell, B. M., Eriyagama, N., Vervoort, J. M., \& Kinyangi, J. (2013). Addressing uncertainty in adaptation planning for agriculture. Proceedings of the National Academy of Sciences of the United States of America, 110(21), 8357-8362. doi.org/10.1073/pnas.1219441110

White, S. N., Boyd, N. S., \& van Acker, R. C. (2012). Growing degree-day models for predicting lowbush blueberry (Vaccinium angustifolium Ait.) ramet emergence, tip dieback, and flowering in Nova Scotia, Canada. HortScience, 47(8), 1014-1021.

Wilson, G. A. (2009). The spatiality of multifunctional agriculture: A human geography perspective. Geoforum, 40, 269-280. doi.org/10.1016/j.geoforum.2008.12.007

Winfree, R., Williams, N. M., Gaines, H., Ascher, J. S., \& Kremen, C. (2008). Wild bee pollinators provide the majority of crop visitation across land-use gradients in New Jersey and Pennsylvania, USA. Journal of Applied Ecology, 45(3), 793-802. doi.org/10.1111/ j.1365-2664.2007.01418.x

Yarborough, D. (2015). Wild blueberry crop statistics. Retrieved from: umaine.edu/blueberries/ factsheets/statistics-2/statistics/ 
This text is taken from Human Ecology Review, Volume 24, Number 1, 2018, published 2018 by ANU Press, The Australian National University, Canberra, Australia.

doi.org/10.22459/HER.24.01.2018.05 